\title{
The effect of preexisting hypertension on early neurologic results of patients with an acute spinal cord injury
}

\author{
CK Kepler ${ }^{1}$, GD Schroeder ${ }^{1}$, ND Martin ${ }^{2}$, AR Vaccaro ${ }^{1}$, M Cohen $^{3}$ and MS Weinstein ${ }^{3}$
}

Study design: Retrospective case-control.

Objectives: To characterize changes in American Spinal Injury Association Motor Score (AMS) in patients treated with relative hypertension (HTN) (mean arterial pressure (MAP) > $85 \mathrm{~mm} \mathrm{Hg}$ for 5 days) with and without preexisting HTN.

Setting: A regional spinal cord injury (SCI) center in Pennsylvania, United States.

Methods: All patients with an acute SCI who were treated with induced HTN (MAP goal above 85) in the intensive care unit (ICU) for at least 5 days were identified. Patients were stratified based on the presence of preexisting HTN, and the change in the AMS between admission and day 5 was determined. Predictors of outcome were identified using correlation analysis and multiple linear regression. Results: Ninety-two patients met inclusion criteria of which 22 had a previous history of HTN. HTN was a predictor of poor early outcome. Patients with HTN had an average decline in their AMS of 7.6, compared with an average decrease of only 0.6 in the AMS of patients without HTN $(P=0.04)$. HTN had no effect $(P>0.05)$ on other in-hospital variables including length of stay, length of stay in the ICU, complications or mortality. Additionally, multiple linear regression analysis demonstrated that diabetes, coronary artery disease and pulmonary disease had no effect on the change in AMS.

Conclusion: Chronic HTN is an independent risk factor for poor early neurologic recovery in patients treated with relative HTN for an acute SCl. This is independent of age and other comorbidities.

Spinal Cord (2015) 53, 763-766; doi:10.1038/sc.2015.76; published online 28 April 2015

\section{INTRODUCTION}

Annually, 230000 patients in the United States suffer an acute spinal cord injury (SCI) and are faced with significant associated sequelae. ${ }^{1,2}$ Furthermore, the global incidence of these devastating injuries has increased to approximately 750 injuries per 1000000 people. $^{3}$ In spite of the rising incidence, the ideal treatment algorithm for patients with an acute SCI remains uncertain.

A primary and secondary mechanism together are responsible for the neurologic injury associated with trauma to the spinal cord. The primary injury results from rapid compression of the spinal cord leading to mechanical damage to the neural tissue. The primary injury also initiates a secondary mechanism, which is a complex biochemical process that causes: ischemia, cell membrane deregulation, capillary rupture, vasospasm, neurotransmitter accumulation, development of free radicals and, possibly, eventual cell death. ${ }^{4-7}$ Although prevention is the only treatment for the primary injury, a combination of surgical and medical treatments can lessen the impact of the secondary injury on ultimate spinal cord function.

The Surgical Timing in Acute Spinal Cord Injury Study (STASCIS) strongly suggests that early decompression improves neurologic function in patients with an acute $\mathrm{SCI},{ }^{8}$ but the role of adjunctive medical treatment is less clear. The use of high dose methylprednisolone came into favor after publication of the National Acute Spinal Cord Injury Study (NASCIS) II demonstrated neurologic improvement in patients who received steroids within $8 \mathrm{~h}$ of the injury. ${ }^{9,10}$
However, in 2014, Schroeder et al. ${ }^{19}$ reported that only $26 \%$ of spine surgeons believe in the efficacy of high dose steroid treatment, and in 2013, the American Association of Neurologic Surgeons/Congress of Neurosurgeons recommended against the use of high dose steroids in an acute SCI. ${ }^{11}$ This is largely due to an increased awareness of the complications associated with high dose steroid use, and the failure of subsequent studies to confirm the results of the NASCIS II. ${ }^{11-19}$ Although alternative neuroprotective pharmacologic treatments, such as riluzole, are being developed and have shown promise in animal trials, ${ }^{20-23}$ clinical trials are still in the early stages. ${ }^{24,25}$

Although the use of different neuroprotective medications is unclear, one of the widely available and accepted treatments used to limit the secondary injury from an acute SCI is ensuring spinal cord perfusion with induced hypertension (HTN). Two studies have demonstrated improved neurologic function and a decrease in mortality in SCI patients who were kept relatively hypertensive. ${ }^{26,27}$ Although no consensus has been established on the exact target blood pressure or treatment duration necessary, clinical protocols often aim to keep the mean arterial pressure (MAP) above $85 \mathrm{~mm} \mathrm{Hg}$ or 90 $\mathrm{mm} \mathrm{Hg}$ for between 5 and 7 days after injury. ${ }^{26-28}$

Whereas a MAP of $85-90 \mathrm{~mm} \mathrm{Hg}$ is an acceptable baseline number, this goal may need to be modified based on patient factors such as preexisting HTN. Chronic HTN has been shown to affect the autoregulation of blood flow to the brain, ${ }^{29,30}$ and although strong scientific evidence establishing the same phenomenon in the spinal

${ }^{1}$ Department of Orthopaedic Surgery, The Rothman Institute at Thomas Jefferson University, Philadelphia, PA, USA; ${ }^{2}$ Department of Surgery, Hospital of the University of Pennsylvania, Philadelphia, PA, USA and ${ }^{3}$ Department of Surgery, Thomas Jefferson University, Philadelphia, PA, USA

Correspondence: Dr G Schroeder, Department of Orthopaedic Surgery, Rothman Institute and Thomas Jefferson University, 925 Chestnut Street, 5th Floor, Philadelphia 19107, PA, USA.

E-mail: gregdschroeder@gmail.com

Received 9 January 2015; revised 9 March 2015; accepted 10 March 2015; published online 28 April 2015 
cord is lacking, animal studies have demonstrated nearly identical autoregulation of blood flow in the brain and spinal cord. ${ }^{31}$ Because of this, ensuring perfusion of the spinal cord may require a higher MAP goal in patients with chronic HTN. The aim of this paper is to determine whether preexisting HTN affects early neurologic outcomes in patients treated with relative HTN who sustained an acute SCI.

\section{METHODS}

After IRB approval was obtained, a retrospective review of a prospectively entered trauma database from a single regional SCI center was performed. All patients admitted with an acute SCI between October 2006 and June 2009 who were treated with induced HTN (MAP goal above 85) in the intensive care unit for at least 5 days were included. Patients were then stratified based on the presence of preexisting HTN.

The primary outcome measure was change in the ASIA motor score (AMS) between admission and day 5 ( $\triangle$ AMS). The AMS was used rather than the ASIA grade, because it allows for the grading of each limb individually. It is therefore more sensitive at detecting differences in neurologic function and is a better indicator of the effects of therapeutic interventions. ${ }^{32,33}$ This score is determined by the summation of the motor grade $(0-5)$ of five key muscle groups in each extremity. ${ }^{34}$

\section{Statistical analysis}

Statistical analysis was performed using SPSS Version 20.0.0 (SPSS, Inc., 2011, Chicago, IL, USA). All data were subjected to descriptive statistical analysis yielding frequency scores for categorical data and mean scores with standard deviations for continuous/interval data. Interval data that were found not to be normally distributed were analyzed via a Mann-Whitney $U$ test to compare medians. Statistically significant differences were evaluated by conducting inferential statistical analysis using the Chi-Square test or Fisher's Exact test for categorical variable comparisons and the Student's $t$-test or analysis of variance for continuous/interval data comparisons. Additionally, multiple linear regression analysis was performed on the effect of medical comorbidities including HTN, diabetes, coronary artery disease and pulmonary disease on the change in AMS. A $P$-value less than or equal to 0.05 was considered statistically significant.

\section{RESULTS}

A total of 92 patients were identified who met the inclusion criteria, of which 22 had a previous history of HTN as reported by the patient/ family and 70 patients had no prior history of HTN. Despite a target MAP of $85 \mathrm{~mm} \mathrm{Hg}$ for all patients, only $52.6 \%$ of the patients with HTN and $46.4 \%$ of patients without HTN had a mean MAP greater than $85 \mathrm{~mm} \mathrm{Hg}$ for 5 days $(P=0.50)$. No difference in mechanism of injury $(P=0.09)$ or the level of spinal injury $(P=0.76)$ was identified between the two cohorts (Table 1). Additionally, there was no difference in the gender $(P=0.10)$, injury severity score $(P=0.10)$, number of patients undergoing surgery $(P=0.07)$, number of patients with a complete SCI $(P=0.30)$ or the AMS on admission $(P=0.70)$ (Table 2) between the two groups. The only statistically different variable identified between the two groups was that the HTN group was significantly older than the non-HTN group (70.0 versus 46.5, $P=0.00001)$.

HTN was an independent predictor of poor outcome, as patients with HTN had an average decline in their AMS of 7.6, compared with an average decrease of only 0.6 in the AMS of patients without HTN $(P=0.04)$. Although the study was not adequately powered to compare patients within the HTN group, a nonsignificant $(P=0.60)$ trend was identified. Patients with HTN and an average MAP greater than $85 \mathrm{~mm} \mathrm{Hg}$ had a decrease in their AMS by $6.4+/-7.4$ compared with a decrease of $10.5+/-18.9$ for patients with HTN and an average MAP less than $85 \mathrm{~mm} \mathrm{Hg}$.

Table 1 Mechanism of injury and spinal region of patients with a spinal cord injury

\begin{tabular}{lccc}
\hline & Total $\mathrm{n}=92,(\%)$ & Patients with preexisting HTN $\mathrm{n}=22,(\%)$ & Patients with no preexisting HTN $\mathrm{n}=70,(\%)$ \\
\hline Mechanism of injury & & & P value \\
Fall from height & $51(55.4)$ & $18(81.8)$ & $33(47.1)$ \\
Motor vehicle accident & $32(34.8)$ & 0 & $29(41.4)$ \\
Other & $5(5.4)$ & & $5(6.8)$ \\
& & $13(59.1)$ & $44(62.9)$ \\
Level of spinal injury & $57(62)$ & $1(4.5)$ & $4(5.7)$ \\
Cervical & $5(5.4)$ & $2(9.1)$ & $14(20)$ \\
Thoracic & $16(17.4)$ & $2(9.1)$ & 0 \\
Cervical and thoracic & $2(2.2)$ & $4(18.2)$ & $2(2.9)$ \\
Cervical and lumbar & $6(6.5)$ & 0 & $4(5.7)$ \\
Cervical, thoracic and lumbar & $4(4.3)$ & 0 & $1(1.4)$ \\
Thoracic and lumbar & $1(1.4)$ & 0.76 \\
Thoracic, sacral & & & \\
\hline
\end{tabular}

Abbreviation: HTN, hypertension.

Table 2 Patient-specific variables for patients with and without hypertension

\begin{tabular}{|c|c|c|c|c|}
\hline & Total $\mathrm{n}=92$ & Patients with preexisting $H T N \mathrm{n}=22$ & Patients with no preexisting $H T N \mathrm{n}=70$ & $\mathrm{P}$ value \\
\hline Males, $n(\%)$ & $67(72.8)$ & $13(59.1)$ & $54(77.1)$ & 0.10 \\
\hline Age, median (IQR) & $52.5(38.50-72.25)$ & $70.0(60.0-80.2)$ & $46.5(32.8-63.5)$ & $0.00001^{a}$ \\
\hline Injury severity score at admission, median (IQR) & $25.5(17.0-33.3)$ & $20.0(17.0-26.0)$ & $26.0(17.0-35.0)$ & 0.10 \\
\hline Patients with a complete spinal cord injuries, $n(\%)$ & $27(29.3)$ & $7(31.8)$ & $20(28.6)$ & 0.30 \\
\hline AMS on admission, mean (s.d.) & $33.7(26.9)$ & $35.5(29.5)$ & $33.2(26.3)$ & 0.70 \\
\hline Number of patients who underwent surgery, $n(\%)$ & 79 (85.9) & $16(72.7)$ & $63(90)$ & 0.07 \\
\hline
\end{tabular}

Abbreviations: AMS, American Spinal Injury Association Motor Score; HTN, hypertension; IQR, interquartile range.

aStatistically significant. 
Table 3 Non-neurologic outcome variables

\begin{tabular}{|c|c|c|c|c|}
\hline & Total $\mathrm{n}=92,(\%)$ & Patients with preexisting $H T N \mathrm{n}=22$, (\%) & Patients with no preexisting $H T N \mathrm{n}=70$, (\%) & $\mathrm{P}$ value \\
\hline Days in the ICU, median (IQR) & $6(3-15)$ & $6(3-12.75)$ & $6(3-15.25)$ & 0.8 \\
\hline Complications, $n(\%)$ & $40(43.5)$ & $10(45.5)$ & $30(42.9)$ & 0.5 \\
\hline Mortality, $n(\%)$ & $13(14.1)$ & $5(22.7)$ & $8(11.4)$ & 0.2 \\
\hline
\end{tabular}

Abbreviations: HTN, hypertension; ICU, intensive care unit; IQR, interquartile range.

Because the patients with HTN were significantly older, multiple linear regression analysis was performed using HTN and age as the independent variables and the change of AMS as the dependent variable. The analysis demonstrated that age was not a significant predictor of the change in AMS (coefficient 0.1, $P=0.14$ ); however, HTN was a significant predictor of a decrease in AMS independent of age (coefficient $-9.4, P=0.014$ ). Additionally, multiple linear regression analysis was performed on the effect of medical comorbidities including HTN, diabetes, coronary artery disease and pulmonary disease on the change in AMS, and only HTN was identified as a significant predictor of a change in AMS (coefficient - 7.5, $P=0.039$ ).

Although HTN was a predictor of decreased early neurologic recovery, it did not demonstrate a significant $(P>0.05)$ effect on other variables including: time on a ventilator, length of intensive care unit stay, length of hospital admission, occurrence of significant complication or mortality (Table 3 ).

\section{DISCUSSION}

The goal of this study was to determine whether preexisting HTN affects early neurologic outcomes in patients treated with relative HTN who sustained an acute SCI, and we found a statistically significant decrease in early neurologic recovery in patients with chronic HTN. Furthermore, the presence of other comorbidities such as diabetes and coronary artery disease that may be other markers for small vessel disease did not affect neurologic recovery, and in a regression analysis, the effect of preexisting HTN on neurologic recovery was found to be an independent predictor of neurologic recovery.

The results of this study may be due to the effect of chronic HTN on the autoregulation of blood flow to the central nervous system. This phenomenon has been well established in the brain. ${ }^{29,30,35}$ Autoregulation of the cerebral perfusion pressure (MAP_intracranial pressure) allows for a constant blood flow to the brain of approximately $50 \mathrm{ml}$ per $100 \mathrm{~g}$ brain tissue per minute despite blood pressure variability. ${ }^{35}$ However, when cerebral perfusion pressure (CPP) falls below $50 \mathrm{~mm} \mathrm{Hg}$ or rises above $150 \mathrm{~mm} \mathrm{Hg}$, the body is no longer able to maintain a consistent blood flow to the brain..$^{29,30,35}$ In patients with chronic HTN, the body adapts by shifting this curve to the right, allowing the body to maintain proper blood flow to the brain at higher MAPs, but making the body unable to ensure perfusion at lower MAPs. ${ }^{29,30,35}$ An understanding of this has lead to elevated blood pressure goals in patients with chronic HTN having an acute stroke, ${ }^{29,30,35}$ and the current study indicates that a similar approach is needed in patients with chronic HTN who suffer from an acute SCI.

Vale et al. ${ }^{27}$ reported on the treatment of 77 patients with an acute SCI who had their MAPs kept above $85 \mathrm{~mm} \mathrm{Hg}$, and they found clinical improvement in $92 \%$ of patients with an incomplete SCI, and $60 \%$ of patients with a complete injury after 1 year. Similarly, Levi et $a l .{ }^{26}$ reported on 50 patients with an acute SCI. The maps of all these patients was kept above $90 \mathrm{~mm} \mathrm{Hg}$, and $42 \%$ demonstrated clinical recovery. The clinical results of both these studies demonstrated improved outcomes compared with historic controls, but neither study stratified patients based on preexisting HTN. Our study indicates that MAP parameters set forth in aforementioned studies may be inadequate to maintain perfusion to the spinal cord in patients with chronic HTN.

The primary limitation to this study is that it only reports on the early neurologic recovery and does not report on the recovery 1-2 years after the injury. Although inevitably some of the patients will begin to demonstrate neurologic recovery over time, we feel that the statistically significant decrease in AMS in patients with chronic HTN is likely the result of less effective spinal cord perfusion. This study lays the groundwork for further studies to evaluate the effect of chronic HTN on blood flow to the spinal cord, and on ideal MAP parameters in patients with chronic HTN who sustain an acute SCI. Another limitation is that undoubtedly there are some variables that were not accounted for in this study, such as a possible difference in spinal cord perfusion with the use of different medications to induce HTN. Additionally, whereas treatment for all patients began as soon as the neurointensivists evaluated the patient (within an hour of presentation to the emergency room), a specific time from the injury to the onset of induced HTN was not able to be determined. Although the records clearly identify that the injury was an acute injury, it is unclear whether the injury happened $30 \mathrm{~min}$ or $4 \mathrm{~h}$ ago. Furthermore, it is possible that some of the patients with HTN had very well-controlled HTN, and thus they might not have had any changes to their vascular system. Similarly, there are likely some patients in the non-HTN group who in fact had undiagnosed HTN. However, both of these misclassifications would likely lead to a smaller difference in the groups, and our results demonstrate clear statistical significance.

\section{CONCLUSION}

Chronic HTN is an independent risk factor for poor early neurologic recovery in patients who sustain an acute SCI. This is independent of age and other comorbidities. Future studies need to be performed to identify the role HTN has on the autoregulation of blood flow to the spinal cord and on ideal MAP parameters for patients with preexisting HTN who sustain an acute SCI.

\section{DATA ARCHIVING}

There were no data to deposit.

\section{CONFLICT OF INTEREST}

The authors acknowledge the following conflicts: Christopher Kepler -Consultant for Healthgrades Inc. Gregory Schroeder-Received fund to travel to meetings from Medtronic. Alexander VaccaroConsultant: Medtronic, Stryker, Globus, Stout, Gerson Lehrman Group, Guidepoint Global, Medacorp, Innovative Surgical Design, Orthobullets, Expert testimony, Ellipse. Service on Scientific Advisory 
Board / Board of Directors / Service on Committees: Innovative Surgical Design, Spinicity. Royalites: Thieme, Jaypee, Elseviere, Taylor Francis, Aesculap, Globus, Medtronic, Stryker, DePuy. Institutional Support: Cerapedics. Stocks: Spine Medica, Computational Biodynamics, Progressive Spinal Technologies, Spinology, Small Bone Innovations, Cross Current, In Vivo, Flagship Surgical, Advanced Spinal Intellectual Properties, Cytonics, Bonovo Orthopaedics, Electrocore, Gamma Spine, Location Based Intelligence, FlowPharma, R.S. I., Replication Medica, Globus, Stout Medical, Rothman Institute and Related Properties, Innovative Surgical Design, Spinicity. Niels D Martin, Murray Cohen and Michael S Weinstein report no conflicts.

1 Chiles BW 3rd, Cooper PR. Acute spinal injury. N Engl J Med 1996; 334: 514-520.

2 Nobunaga AI, Go BK, Karunas RB. Recent demographic and injury trends in people served by the Model Spinal Cord Injury Care Systems. Arch Phys Med Rehabil 1999; 80: $1372-1382$.

3 Wyndaele M, Wyndaele JJ. Incidence, prevalence and epidemiology of spinal cord injury: what learns a worldwide literature survey? Spinal Cord 2006; 44: 523-529.

4 Tator $\mathrm{CH}$, Fehlings MG. Review of the secondary injury theory of acute spinal cord trauma with emphasis on vascular mechanisms. J Neurosurg 1991; 75: 15-26.

5 Amar AP, Levy ML. Pathogenesis and pharmacological strategies for mitigating secondary damage in acute spinal cord injury. Neurosurgery 1999; 44 1027-1039 discussion 1039-40.

6 Profyris C, Cheema SS, Zang D, Azari MF, Boyle K, Petratos S. Degenerative and regenerative mechanisms governing spinal cord injury. Neurobiol Dis 2004; 15 415-436.

7 Sekhon LH, Fehlings MG. Epidemiology, demographics, and pathophysiology of acute spinal cord injury. Spine (Phila Pa 1976) 2001; 26 (24 Suppl): S2-12.

8 Fehlings MG, Vaccaro A, Wilson JR, Singh A, W Cadotte D, Harrop JS et al. Early versus delayed decompression for traumatic cervical spinal cord injury: results of the Surgical Timing in Acute Spinal Cord Injury Study (STASCIS). PLoS One 2012; 7: e32037.

9 Bracken MB, Shepard MJ, Collins WF, Holford TR, Young W, Baskin DS et al. A randomized, controlled trial of methylprednisolone or naloxone in the treatment of acute spinal-cord injury. Results of the Second National Acute Spinal Cord Injury Study. N Engl J Med 1990; 322: 1405-1411.

10 Bracken MB, Shepard MJ, Holford TR, Leo-Summers L, Aldrich EF, Fazl M et al. Administration of methylprednisolone for 24 or $48 \mathrm{~h}$ or tirilazad mesylate for 48 hours in the treatment of acute spinal cord injury. Results of the Third National Acute Spinal Cord Injury Randomized Controlled Trial. National Acute Spinal Cord Injury Study. JAMA 1997; 277: 1597-1604.

11 Hurlbert RJ, Hadley MN, Walters BC, Aarabi B, Dhall SS, Gelb DE et al. Pharmacological therapy for acute spinal cord injury. Neurosurgery 2013; 72 (Suppl 2): 93-105.

12 Hurlbert RJ. Methylprednisolone for acute spinal cord injury: an inappropriate standard of care. J Neurosurg 2000; 93 (1 Suppl): 1-7.

13 Hurlbert RJ. The role of steroids in acute spinal cord injury: an evidence-based analysis. Spine (Phila Pa 1976) 2001; 26 (24 Suppl): S39-S46.

14 Matsumoto T, Tamaki T, Kawakami M, Yoshida M, Ando M, Yamada H. Early complications of high-dose methylprednisolone sodium succinate treatment in the follow-up of acute cervical spinal cord injury. Spine (Phila Pa 1976) 2001; 26: 426-430.

15 Molano Mdel R, Broton JG, Bean JA, Calancie B. Complications associated with the prophylactic use of methylprednisolone during surgical stabilization after spinal cord injury. J Neurosurg 2002; 96 (3 Suppl): 267-272.
16 Leypold BG, Flanders AE, Schwartz ED, Burns AS. The impact of methylprednisolone on lesion severity following spinal cord injury. Spine (Phila Pa 1976) 2007; 32 373-378 discussion 379-81.

17 Ito Y, Sugimoto Y, Tomioka M, Kai N, Tanaka M. Does high dose methylprednisolone sodium succinate really improve neurological status in patient with acute cervical cord injury?: a prospective study about neurological recovery and early complications. Spine (Phila Pa 1976) 2009; 34: 2121-2124.

18 Pollard ME, Apple DF. Factors associated with improved neurologic outcomes in patients with incomplete tetraplegia. Spine (Phila Pa 1976) 2003; 28 33-39.

19 Schroeder GD, Kwon BK, Eck JC, Savage JW, Hsu WK, Patel AA. Survey of cervical spine research society members on the use of high-dose steroids for acute spinal cord injuries. Spine (Phila Pa 1976) 2014; 39: 971-977.

20 Wu Y, Satkunendrarajah K, Teng Y, Chow DS, Buttigieg J, Fehlings MG. Delayed postinjury administration of riluzole is neuroprotective in a preclinical rodent model of cervical spinal cord injury. J Neurotrauma 2013; 30: 441-452.

21 Tator CH, Hashimoto R, Raich A, Norvell D, Fehlings MG, Harrop JS et al. Translational potential of preclinical trials of neuroprotection through pharmacotherapy for spinal cord injury. J Neurosurg Spine 2012; 17 (1 Suppl): 157-229.

22 Simard JM, Tsymbalyuk O, Keledjian K, Ivanov A, Ivanova S, Gerzanich V. Comparative effects of glibenclamide and riluzole in a rat model of severe cervical spinal cord injury. Exp Neurol 2012; 233: 566-574.

23 Samano C, Nasrabady SE, Nistri A. A study of the potential neuroprotective effect of riluzole on locomotor networks of the neonatal rat spinal cord in vitro damaged by excitotoxicity. Neuroscience 2012; 222: 356-365.

24 Grossman RG, Fehlings MG, Frankowski RF, Burau KD, Chow DS, Tator C et al. A prospective, multicenter, phase I matched-comparison group trial of safety, pharmacokinetics, and preliminary efficacy of riluzole in patients with traumatic spinal cord injury. J Neurotrauma 2014; 31: 239-255.

25 Fehlings MG, Wilson JR, Karadimas SK, Arnold PM, Kopjar B. Clinical evaluation of a neuroprotective drug in patients with cervical spondylotic myelopathy undergoing surgical treatment: design and rationale for the CSM-Protect trial. Spine (Phila Pa 1976) 2013; 38 (22 Suppl 1): S68-S75.

26 Levi L, Wolf A, Belzberg H. Hemodynamic parameters in patients with acute cervical cord trauma: description, intervention, and prediction of outcome. Neurosurgery 1993; 33: 1007-1016 discussion 1016-7.

27 Vale FL, Burns J, Jackson AB, Hadley MN. Combined medical and surgical treatment after acute spinal cord injury: results of a prospective pilot study to assess the merits of aggressive medical resuscitation and blood pressure management. J Neurosurg 1997 87: 239-246

28 Casha S, Christie S. A systematic review of intensive cardiopulmonary management after spinal cord injury. J Neurotrauma 2011; 28: 1479-1495.

29 Owens WB. Blood pressure control in acute cerebrovascular disease. J Clin Hypertens (Greenwich) 2011; 13: 205-211.

30 Gorelick PB, Aiyagari V. The management of hypertension for an acute stroke: what is the blood pressure goal? Curr Cardiol Rep 2013; 15: 366.

31 Hickey R, Albin MS, Bunegin L, Gelineau J. Autoregulation of spinal cord blood flow: is the cord a microcosm of the brain? Stroke 1986; 17: 1183-1189.

32 Marino RJ, Graves DE. Metric properties of the ASIA motor score: subscales improve correlation with functional activities. Arch Phys Med Rehabil 2004; 85: 1804-1810.

33 Fawcett JW, Curt A, Steeves JD, Coleman WP, Tuszynski MH, Lammertse D et al. Guidelines for the conduct of clinical trials for spinal cord injury as developed by the ICCP panel: spontaneous recovery after spinal cord injury and statistical power needed for therapeutic clinical trials. Spinal Cord 2007; 45: 190-205.

34 Kirshblum SC, Burns SP, Biering-Sorensen F, Donovan W, Graves DE, Jha A et al. International standards for neurological classification of spinal cord injury (revised 2011). J Spinal Cord Med 2011; 34: 535-546.

35 Powers WJ. Acute hypertension after stroke: the scientific basis for treatment decisions. Neurology 1993; 43 (3 Pt 1): 461-467. 